\title{
Long-term follow-up of retinal blood flow in diabetes using the blue light entoptic phenomenon
}

\author{
TIM RIMMER, TIMOTHY J FALLON, AND EVA M KOHNER \\ From the Department of Medicine, Royal Postgraduate Medical School, London
}

SUMMARY The blue light entoptic phenomenon was used to measure retinal blood flow in 87 diabetics and 10 normal controls in a longitudinal study. The time interval between the initial and final studies was 21-39 months (mean 31-4). The retinal blood flow velocity did not change in the 10 subjects in the control group nor in those nine patients with no retinopathy, all but one of whom remained free of retinal lesions. In the 24 with background retinopathy the flow velocity fell significantly from 0.71 (SD 0.35$) \mathrm{mm} / \mathrm{s}$ to $0.48(0.13) \mathrm{mm} / \mathrm{s}(\mathrm{p}<0.01)$. The velocity also decreased in the preproliferative group of 16 patients from $0.62(0.39) \mathrm{mm} / \mathrm{s}$ to $0.41(0.14) \mathrm{mm} / \mathrm{s}(\mathrm{p}<0.05)$. The retinopathy status changed in 11 of this group. In those with proliferative retinopathy (now treated) and those treated previously there was no change in flow velocity.

To understand the changes of retinal blood flow in diabetic retinopathy is important because it will further our understanding of the pathophysiology of the condition and perhaps reveal processes amenable to therapy in the earliest stages of the disease. Diabetic retinopathy is now the commonest cause of blindness under the age of 65 in the United Kingdom. ${ }^{1}$

Retinal blood flow in diabetes will vary in response to changes in metabolic demands and may vary with the histopathological features of early retinopathy, namely generalised pericyte loss, basement membrane thickening, endothelial proliferation, and microaneurysm formation, particularly affecting the venous end of the capillary bed. ${ }^{2}$ Flow is also affected by endothelial cell loss.

The exact effects of diabetic retinopathy on retinal blood flow are not established in spite of extensive investigations with fluorescein dye dilution techniques, ${ }^{34}$ laser doppler velocimetry, ${ }^{5-7}$ and blue field entoptoscopy. ${ }^{8}$ This is probably due to the selection of patients and the fact that different methods measure different aspects of flow. Long-term followup to show changes in blood flow in large numbers of patients has not been carried out previously. In this study we report such changes in 87 diabetics and 10 normal subjects using the blue light entoptic technique.

Correspondence to Eva M Kohner, MD, Royal Postgraduate Medical School, Hammersmith Hospital, Du Cane Road, London W12 0HS.

\section{Patients and methods}

\section{PATIENTS}

Of the 126 diabetics whose retinal blood flow was measured in 1984 by the same method and described in an earlier study 87 were available for reassessment two years later. Ten of the 24 healthy volunteers were also available. Of the remaining 37 diabetics eight had died, two had gone abroad, six could not repeat the test because of vitreous haemorrhage, maculopathy, or poor concentration, and 23 were either not reassessed or could not be contacted. A visual acuity of at least $6 / 12$ was necessary to see the simulated leucocytes clearly on the TV monitor.

On entering the first study all patients had undergone a screening procedure to assess their ability to match the speed of the simulated leucocytes with the speed of their own leucocytes seen in the entoptoscope. Only those achieving reproducibility scores of at least $80 \%$ were included in this investigation.

The diabetic patients were divided into the following groups based on the level of retinopathy at the first measurement assessed ophthalmoscopically or by colour retinal photographs: (1) no retinopathy; (2) background retinopathy (from one microaneurysm only to multiple microaneurysms, haemorrhages, and hard exudates); (3) preproliferative retinopathy (as (2) plus cotton-wool spots, intraretinal microvascular abnormalities, venous abnormalities of severe degree, but no new vessels); (4) proliferative retinopathy (disc new vessels and/or new vessels 
Table 1 Patient details at first assessment

\begin{tabular}{lrll}
\hline Retinal category & Number & $\begin{array}{l}\text { Mean age, } \\
\text { years (range) }\end{array}$ & $\begin{array}{l}\text { Mean duration of } \\
\text { diabetes mellitus, } \\
\text { years (range) }\end{array}$ \\
\hline Normal controls & 10 & $32(27-38)$ & - \\
No retinopathy & 9 & $37(20-51)$ & $10(2 / 52-27)$ \\
Background & 24 & $44(23-65)$ & $20(5-43)$ \\
Preproliferative & 16 & $43(23-53)$ & $13(2-30)$ \\
Proliferative & 13 & $38(24-58)$ & $23(14-42)$ \\
Photocoagulated & 25 & $46(19-67)$ & $24(2-41)$ \\
\hline
\end{tabular}

elsewhere); (5) postphotocoagulation (no new vessels remaining after argon or xenon treatment). Argon laser photocoagulation would mean at least 2000 burns of an intensity aiming at a pale grey lesion, each burn being $200-500 \mu \mathrm{m}, 0 \cdot 15-0.30$ watt, and $0.05-0.1$ second. Four of the patients had xenon treatment in addition which involved at least 150 burns of aperture $4.5 \mathrm{~mm}$, power $4-15 \mathrm{~W}$, and duration 1.0 second. For patients details see Table 1.

\section{METHODS}

The blue light entoptic method has been described in our earlier cross-sectional study, ${ }^{8}$ so a brief description only will be given here. The subject matches the speed of a pattern of simulated leucocytes presented by a computer on a TV monitor with the speed of his own seen entoptically in the perifoveal capillaries when he looks into a blue light of wavelength $430 \mathrm{~nm}$. The retinal speed is calculated from the TV screen speed and the subject repeats the test until three consecutive readings are obtained whose maximum deviation from the mean is less than $20 \%$.
Table 2 Retinal blood flow velocities at start and end of 30 month period

\begin{tabular}{llll}
\hline $\begin{array}{l}\text { Retinal category } \\
\text { at first } \\
\text { assessment }\end{array}$ & $\begin{array}{l}\text { Start } \\
\text { mean } \mathrm{mm} / \mathrm{s} \\
(S D)\end{array}$ & $\begin{array}{l}\text { End } \\
\text { mean } \mathrm{mm} / \mathrm{s} \\
(S D)\end{array}$ & $\begin{array}{l}\text { Mean duration } \\
\text { between readings } \\
\text { months (range) }\end{array}$ \\
\hline Normal Controls & $\mathbf{0 . 5 7 ( 0 \cdot 1 9 )}$ & $0.65(0 \cdot 11)$ & $30(29-31)$ \\
No retinopathy & $\mathbf{0 . 4 7}(0 \cdot 22)$ & $0 \cdot 57(0 \cdot 27)$ & $32(24-37)$ \\
Background & $\mathbf{0 . 7 1 ( 0 \cdot 3 5 )}$ & $0.48(0 \cdot 13)$ & $33(24-38)$ \\
Preproliferative & $\mathbf{0 . 6 2 ( 0 \cdot 3 9 )}$ & $\mathbf{0 . 4 1}(0 \cdot 14)$ & $32(21-39)$ \\
Proliferative & $0.58(0 \cdot 26)$ & $0.47(0 \cdot 21)$ & $27(21-35)$ \\
Photocoagulated & $0.46(0 \cdot 14)$ & $0.45(0 \cdot 09)$ & $32(23-38)$ \\
\hline
\end{tabular}

Colour photographs at the beginning and end of the study of patients in the background retinopathy group were graded by the Hammersmith Hospital system, which is based on standard photographs." Photographs were graded for microaneurysms/ haemorrhages and hard exudates in each of five fields. The maximum score for each of these two categories for each eye was 25 .

Blood pressure, blood sugar (Beckmann glucose analyser; Clinical Instruments Division, 2500 Harbor Boulevard, Fullerton, California 92634, USA), and HbA1 levels (Corning densitometer; Corning Medical and Scientific, Corning Glass Works, Medfield, Maryland 02052, USA) were recorded each time.

Student's $t$ tests (paired when appropriate) and Wilcoxon's rank sum tests were used to assess the significance of the results, $p$ values of less than 0.05 being considered significant. Coefficients of correlation were calculated by the least squares method.
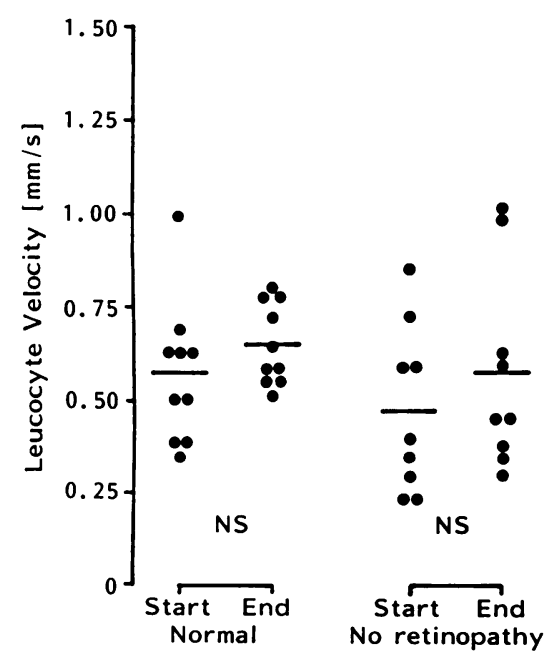

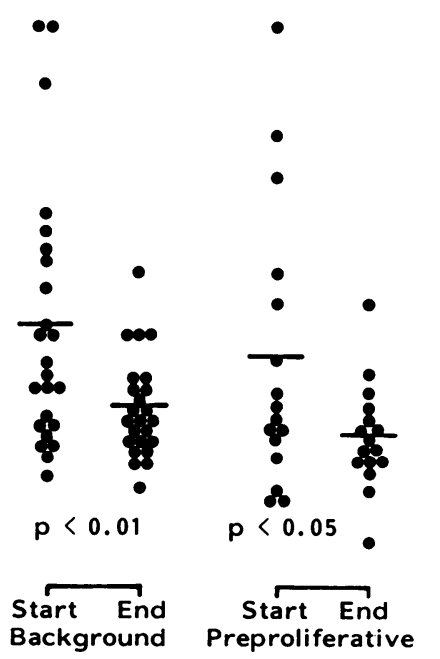

Retinopathy at Start

Fig. 1 Perifoveal leucocyte velocities of diabetics and normal controls at start and end of 30-month period (NS=not significant). 


\section{Results}

There was no significant change in the retinal flow velocity of the 10 normal subjects, being 0.57 (SD $0.19) \mathrm{mm} / \mathrm{s}$ at the start and $0.65(0.11) \mathrm{mm} / \mathrm{s}$ at the end (Table 2). The velocities of seven had increased and three decreased. The flow velocities of the diabetics with no retinopathy also showed no consistent change $(0.47(0.22) \mathrm{mm} / \mathrm{s}$ to $0.57(0.27)$ $\mathrm{mm} / \mathrm{s}$ ), seven increasing and two decreasing. One of this group developed background retinopathy during the study and his velocity increased slightly.

Patients with background retinopathy showed a significant decrease in flow velocity from $0.71(0.35)$ $\mathrm{mm} / \mathrm{s}$ to $0.48(0 \cdot 13) \mathrm{mm} / \mathrm{s}(\mathrm{p}<0.01)$. The flow velocity at the end of the study was also significantly slower than that of normals at the end of the study $(p<0.01$, Fig. 1). Their mean retinopathy grading scores for microaneurysms and haemorrhages changed from $4.83(3.48)$ to $3.83(3.43)$ (not significant, NS). Eight scores worsened, 12 improved, and four remained the same. The mean scores for exudates changed from $1.16(1.34)$ to $1.37(1.47)$ (NS). Nine scores worsened, six improved, and nine were unchanged.

The scores for microaneurysms and haemorrhages at the start of the study correlated well with those at the end of the study $r=0.74, p<0.001$. The scores for exudates at the start of the study also correlated well with those at the end of the study, $r=0.74, p<0.001$. There was no correlation between change in retinal blood flow and retinopathy, blood pressure, or HbA1.

However, six were tested before continuous subcutaneous insulin infusion (CSII) was started and at the last study had all been on CSII for at least 24 months. When these six were taken separately their flow velocity showed an insignificant change from $0.69(0.45) \mathrm{mm} / \mathrm{s}$ to $0.57(0.20) \mathrm{mm} / \mathrm{s}$, whereas the flow velocity of the patients on conventional therapy fell from $0.71(0.33) \mathrm{mm} / \mathrm{s}$ to $0.45(0.08) \mathrm{mm} / \mathrm{s}$ $(p<0 \cdot 01)$. At the end of the study the flow velocity of the patients on CSII was faster than that of patients on conventional therapy $(p<0 \cdot 05)$. There was no significant change in retinopathy scores during the study in either of the above two subgroups.

Taken as a group, the patients with preproliferative retinopathy showed a decrease in flow velocity from $0.62(0.39) \mathrm{mm} / \mathrm{s}$ to $0.41(0.14) \mathrm{mm} / \mathrm{s}(\mathrm{p}<0.05)$. Of these 16 patients two improved to background retinopathy, in five the retinopathy remained preproliferative, two developed new vessels which remained proliferative in spite of treatment, and seven had developed new vessels which regressed completely after photocoagulation. Flow changes were not consistent with changes in retinopathy (Fig. 2).

The patients in the original proliferative retinopathy group had all undergone photocoagulation and showed an insignificant change in flow velocity from $0.58(0.26) \mathrm{mm} / \mathrm{s}$ to $0.47(0.21) \mathrm{mm} / \mathrm{s}$. The mean flow velocity of the photocoagulation group was 0.46 $(0.14) \mathrm{mm} / \mathrm{s}$ at the start and $0.45(0.09) \mathrm{mm} / \mathrm{s}$ at the end, showing no change.

No significant changes were found in the levels of blood sugar, $\mathrm{HbA1}$, and blood pressure, in any of the groups over the study period (Table 3 ). No correlation was found between leucocyte velocity and any of these parameters.

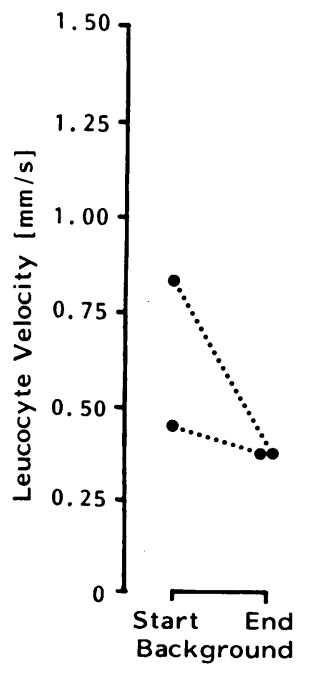

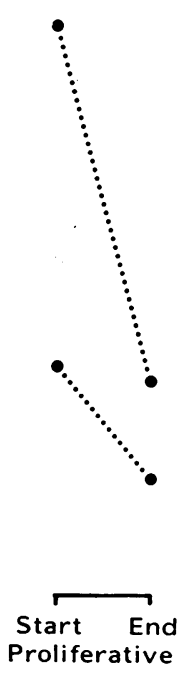

Retinopathy at End

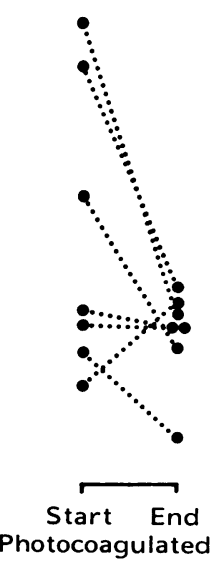

Fig. 2 Perifoveal leucocyte velocities at start and end of 30 month period of 16 patients with preproliferative retinopathy at the start. There were no significant differences between the subgroups. 
Table 3 Blood pressure, $\mathrm{HbAl}$, and blood glucose at start $(S)$ and end $(E)$ of 30-month period

\begin{tabular}{|c|c|c|c|c|}
\hline $\begin{array}{l}\text { Retinal } \\
\text { category } \\
\text { at start }\end{array}$ & $\begin{array}{l}H b A 1 \\
\text { mean }(S D) \\
\text { percentages }\end{array}$ & $\begin{array}{l}\text { Syst. BP } \\
\text { mean }(S D) \\
(\mathrm{mmHg})\end{array}$ & $\begin{array}{l}\text { Diast. BP } \\
\text { mean }(S D) \\
(m m H g)\end{array}$ & $\begin{array}{l}\text { Blood glucose } \\
\text { mean (SD) } \\
\text { (mmol/l) }\end{array}$ \\
\hline \multirow[t]{2}{*}{ No retinopathy } & S $8.5(1.6)$ & $125(9)$ & $80(5)$ & $12 \cdot 9(4 \cdot 1)$ \\
\hline & E $9.2(1.1)$ & $118(14)$ & $73(8)$ & $13.9(4 \cdot 6)$ \\
\hline \multirow[t]{2}{*}{ Background } & S $9.7(1.8)$ & $130(19)$ & $82(12)$ & $9 \cdot 3(3 \cdot 8)$ \\
\hline & E $9.6(1.9)$ & $138(29)$ & $82(11)$ & $11 \cdot 2(4 \cdot 5)$ \\
\hline \multirow[t]{2}{*}{ Preprolif. } & S $9.5(1.9)$ & $141(21)$ & $85(11)$ & $9 \cdot 9(5 \cdot 1)$ \\
\hline & E $10.2(1.8)$ & $136(30)$ & $78(12)$ & $9.6(6.4)$ \\
\hline \multirow{2}{*}{ Prolif. } & S $10.9(2.6)$ & $136(21)$ & $83(13)$ & $11 \cdot 2(4 \cdot 3)$ \\
\hline & E $9.8(1.0)$ & $158(13)$ & $83(8)$ & $8 \cdot 7(5 \cdot 1)$ \\
\hline \multirow[t]{2}{*}{ Photocoag. } & $S 10 \cdot 2(1 \cdot 8)$ & $135(26)$ & $79(9)$ & $10 \cdot 5(6 \cdot 1)$ \\
\hline & E $10.5(2.2)$ & $145(20)$ & $78(11)$ & $9 \cdot 8(5 \cdot 1)$ \\
\hline
\end{tabular}

\section{Discussion}

Studies on retinal blood flow in early diabetes with and without retinopathy using fluorescein dye dilution techniques showed an increase in comparison with normals. ${ }^{34}$ However, this method is no longer used, as it has many shortcomings. It is invasive and measures primarily plasma flow, and even in the absence of ophthalmoscopic changes there is difficulty in assessing the volume of the vascular bed.

Laser doppler studies of retinal blood flow are based on axial velocity of red blood cells in major retinal vessels in relation to the cardiac cycle. ${ }^{5-7}$ This is probably the best and most reproducible method available, but like the other methods it suffers from the inaccuracies caused by changes in the vessel diameter. The changes in axial velocity pulsatility in diabetes described by Feke et al. ${ }^{6}$ could merely be reflecting changes in vessel wall elasticity rather than changes in true volume flow.

The blue light entoptic technique used in this study measures leucocyte velocity in the perifoveal capillaries and is subject to the same limitations in that changes in capillary diameter are unknown. This is probably important, as the macular capillary diameter is smaller than that of leucocytes, which in addition are the least deformable component of blood. The method is also the most subjective but has been shown to be reproducible in practice. ${ }^{8}$

Patients in the background retinopathy group showed a decrease in retinal flow velocity over the 30 month period, and at the end of the study their flow velocity was also significantly slower than that of normals. In diabetes the factors tending to increase blood flow are the increased metabolic rate ${ }^{10}$ and the autoregulatory stimulus of any hypoxia if present, ${ }^{11} 12$ and acute hyperglycaemia, ${ }^{13}$ though the last has not been confirmed in humans. ${ }^{14}$ The flow would be reduced by a decrease in red cell deformability ${ }^{15-17}$ and an increase in red cell aggregation ${ }^{18}$ and blood viscosity, ${ }^{19}$ none of which were measured in this study. Reduction of flow velocity would also be expected if the retinopathy deteriorated, since flow is significantly reduced in patients with large areas of capillary non-perfusion. ${ }^{8}$

This study failed to show worsening of retinopathy on clinical examination or in colour photographs. Fluorescein angiograms were not done on enough patients, and especially not in the retinal periphery, to allow comment on increasing non-perfusion. However, the results of this study, showing a blood flow velocity slower than that of normals, are in line with those of laser doppler velocimetry studies' which showed reduced red cell velocity at all stages of retinopathy even though volume flow was found to be reduced only in photocoagulated patients.

The flow velocity of the patients on CSII showed an insignificant reduction, whereas that of patients on conventional diabetic therapy fell significantly. This finding supports the view that the ongoing effects of diabetes, which are apparently tending to reduce flow velocity, are less marked in patients on CSII.

The results of the 16 preproliferative patients are even more difficult to explain. While reduction in flow was expected and seen in those who were photocoagulated or developed proliferative retinopathy, it was unexpected in the two patients who improved and reverted to background retinopathy (Fig. 2). It is possible that blood flow is more variable in these patients, but we have not found a reason for this.

The retinal flow velocities of the photocoagulated patients, including those in the original proliferative group who were photocoagulated after the first measurement, were unchanged over the period of the study. This may indicate that the flow was already adjusted to the reduced metabolic demands of the smaller area of viable retinal tissue, or that the vessels were already so damaged that change in flow was impossible, or that perifoveal flow was preserved at the expense of flow to more peripheral areas in the face of further capillary closure. Changes up to $20 \%$ could be missed owing to the sensitivity of the method. It will be observed from Fig. 1 that the significant shifts in flow rate seem to be due to loss of outlying higher values rather than a general overall shift. This may be explained by the change in size of the simulated leucocytes on the TV screen from 4 pixels to 1 pixel between the start and end of the study. This change, which was the result of an irreversible modification to allow greater flexibility in other respects, may have affected the performance of some patients more than others. The smaller spread of values at the end of the study in five out of six groups would suggest that this system was more reliable. 
In conclusion, over a 30-month period retinal blood flow velocity was reduced in diabetics with background retinopathy but remained unchanged in those with normal fundi and those who had undergone photocoagulation previously. This would suggest that, in the presence of background retinopathy, longer duration of diabetes and possibly reduced viable retinal tissue both tend to reduce flow.

This work was supported by a grant from the Royal National Institute for the Blind, the British Diabetic Association, and the Juvenile Diabetes Foundation.

\section{References}

1 Department of Health and Social Security. Blindness and partial sight in England 1969-1976. Reports on Public Health and Medical Subjects No. 129. London: HMSO, 1979.

2 Cunha-Vaz JG. Diabetic retinopathy, human and experimental studies. Trans Ophthalmol Soc UK 1972; 92: 111-24.

3 Yoshida A, Feke GT, Morales-Stoppello J, Collas GD, Goger DG, McMeel JW. Retinal blood flow alterations during progression of diabetic retinopathy. Arch Ophthalmol 1983; 100: 225-7.

4 Kohner EM, Hamilton AM, Saunders SJ, Sutcliffe BA, Bulpitt CJ. The retinal blood flow in diabetes. Diabetologia 1975; 11: $27-$ 33.

5 Grunwald JE, Riva CE, Brucker AJ, Sinclair SH, Petrig BL. Altered retinal vascular response to $100 \%$ oxygen breathing in diabetes mellitus. Ophthalmology 1984; 91: 1447-52.

6 Feke GT, Tagawa H, Yoshida A, et al. Retinal circulatory changes related to retinopathy progression in insulin-dependent diabetes mellitus. Ophthalmology 1985; 92: 1517-22.

7 Grunwald JE, Riva CE, Sinclair SH, Brucker AJ, Petrig BL. Laser doppler velocimetry study of retinal circulation in diabetes mellitus. Arch Ophthalmol 1987; 104: 991-6.
8 Fallon TJ, Chowiencyzk P, Kohner EM. Measurement of retinal blood flow in diabetes by the blue-light entoptic phenomenon. $\mathrm{Br}$ J Ophthalmol 1986; 70: 43-6.

9 Oakley N, Hill DW, Joplin GF, Kohner EM, Fraser TR. Diabetic retinopathy 1 . Assessment of severity and progress by comparison with a set of standard fundus photographs. Diabetologia 1967; 3: 402-5.

10 Horstman P. The oxygen consumption in diabetes mellitus. Acta Med Scand 1951; 139: 326-30.

11 Bresnick GH, DeVenecia G, Myers FL, Harris JA, Davis MD. Retinal ischaemia in diabetic retinopathy. Arch Ophthalmol 1975; 93: 1300-10.

12 Kohner EM. Dynamic changes in the microcirculation of diabetics as related to diabetic microangiopathy. Acta Med Scand 1975; suppl 578: 41-7.

13 Atherton A, Hill DW, Keen H, Young S, Edwards EJ. The effect of acute hyperglycaemia on the retinal circulation of the normal cat. Diabetologia 1980; 18: 233-7.

14 Fallon TJ, Sleightholm MA, Merrick C, Chahal P, Kohner EM. The effect of acute hyperglycaemia on flow velocity in the macular capillaries. Invest Ophthalmol Vis Sci 1987; 28: 1027-30.

15 McMillan DE, Utterback NG, Sparks LL, Bramwell PC. Impaired erythrocyte doublet formation in diabetes. Diabetologia 1981; 21: 575-8.

16 Baba Y, Kai T, Kamada T, Setoyama S, Otsuji S. Higher levels of erythrocyte membrane microviscosity in diabetes. Diabetes 1979; 28: 1138-40.

17 McMillan DE, Utterback NG, La Puma J. Reduced erythrocyte deformability in diabetes. Diabetes 1978; 27: 895-901.

18 Little HL. The role of abnormal hemorheodynamics in the pathogenesis of diabetic retinopathy. Trans Am Ophthalmol Soc 1977; 74: 573-6.

19 Dintenfass L. Blood viscosity factors in severe nondiabetic and diabetic retinopathy. Biorheology 1977; 14: 151-7.

Accepted for publication 26 October 1987. 